Journal of Korean Powder Metallurgy Institute

Vol. 18, No. 2, 2011

DOI: $10.4150 /$ KPMI.2011.18.2.181

\title{
Metal-Polymer Composites and their Characterization
}

\author{
S. M. Lebedev*, O. S. Gefle and M. V. Semenikhin \\ High-Voltage Research Institute of National Research Tomsk Polytechnic University \\ 2 A Lenin Avenue, 634028, Tomsk, Russia
}

(Received February 16, 2011; Revised March 25, 2011; Accepted April 11, 2011)

\begin{abstract}
PVDF was used as a polymeric matrix material in this work. Nickel powders with average particles size of $200 \mathrm{~nm}$ or $72 \mathrm{~nm}$ were used as fillers. PVDF/metal submicro- and nanocomposites were prepared by means of a mixing in twin screw extruder and planetary ball mill, respectively. All samples were prepared by hot pressing method. Their electrical, thermal and morphological properties were examined by dielectric spectroscopy, DSC, FTIR, XRD, optical microscopy and scanning electron microscopy. It was found that all properties of composites were strongly modified depending on the content of metal powders and filler particles size. Particularly, specific volume resistivity of PVDF/Ni composite with $0.2 \mathrm{wt}$.\% of $\mathrm{Ni}$ was increased by factor of $1.5 \sim 4$.
\end{abstract}

Keywords : Nanocomposites, Metal powders, Filler, Structure

\section{Introduction}

Filling a polymeric matrix by fine fillers results in the modification of both the polymer structure and properties of composite materials due to formation of interface at the boundary matrix/filler particles $[1,2]$. Adding of submicro and nanosized fillers into polymeric matrixes may result in enhancement or stabilization of electrical, mechanical and thermal properties of polymeric dielectrics due to the increase in the interphase interaction at the interface matrix/filler [3-7].

Polyvinylidene fluoride (PVDF) is widely used as a matrix for the composite polymeric materials (CPM's) with required properties [4-7]. This polymer possesses a high operating temperature and dielectric strength. High permittivity of PVDF allows achieving both uniform distribution of a local electric field in filled materials and a low dispersion of the complex permittivity at the required frequency range.

Nickel is chemically the more stable metal and therefore its application in polymer/metal composites as a modifying agent is more preferable com- pared to other metal powders such as ferrous, aluminum, copper, etc. Moreover usage of other metal powders can result in acceleration of thermooxidative destruction of polymeric matrices especially halogenated polymers [8].

It is well known that usage of submicro- and nanosized metal powders as fillers can change mechanical, magnetic and electrical properties of polymeric composites in spite of the high conductivity of metal filler [8-11]. According to the adding of $3.5 \mathrm{wt} \%$ nickel powder into polypropylene results in the reduction of spherulite sizes by a factor of 2 compared to that for a pure polypropylene due to the formation of artificial nucleation centers [9]. The author has observed an increase in the tensile strength of a composite material [8]. The elastic and magnetic properties of natural rubber/nickel composites showed an improvement with increase in nickel content [11]. Dielectric permittivity of these composites was found to increase with increase in nickel loading.

The study of electrical, thermal and morphological properties of PVDF/Ni composites is the objec-

*Corresponding Author : [E-mail : serguei_lebedev@hotmail.com] 
tive of this work.

\section{EXperimental Procedure and Samples}

Measurements of the real part $\varepsilon^{\prime}$ of the complex permittivity and loss factor $\tan \delta$ were carried out under $\mathrm{AC}$ voltage $3 \mathrm{~V}$ in the frequency range from $10^{-2} \mathrm{~Hz}$ to $1 \mathrm{MHz}$ by using the Solartron Instrument (Impedance/Gain-Phase Analyzer Solartron 1260+ Dielectric Interface Solartron 1296) [12]. From five to ten measurements per decade over the frequency range were carried out for all samples. Study of the specific volume resistivity was carried out at frequency $10^{-4} \mathrm{~Hz}$ at temperatures $20-100^{\circ} \mathrm{C}$ by means of the Solartron Instrument. Not less than five samples for each composite were tested.

Temperatures and temperature intervals of melting and decomposition of CPM's, the heat flow and a weight loss of samples were measured in the temperature range from 25 to $500^{\circ} \mathrm{C}$ at a heating rate of $3^{\circ} \mathrm{C} / \mathrm{min}$ in an argon atmosphere by means of a combined DSC-DTA-TGA analyzer. From three to five samples of each composite were tested for all test conditions.

FTIR analysis was carried out by means of IR spectrometer Nicolet 5700 at the wavenumber range from 4000 to $400 \mathrm{~cm}^{-1}$.

$\mathrm{X}$-ray diffraction of PVDF and nanocomposites was studied by means of diffractometer Shimadzu XRD-6000.

Morphology of PVDF/metal composites was studied under cross polarized light by means of an optical microscope and a scanning electron microscope. Five samples of each composite material were tested.

Pellets and powder of PVDF (Luoropolymer Ltd., St-Petersburg, Russia) was used as-received as a polymeric matrix in this study. Spherical Ni Powders with average size of 200 and $72 \mathrm{~nm}$ produced by the electric explosion of wires under the high electric field at Adv. Powder Techn. LLC (Tomsk,
Russia) were used as fillers.

PVDF/Ni submicro-composites were prepared by means of a mixing of PVDF pellets and $200 \mathrm{~nm} \mathrm{Ni}$ particles in a twinscrew extruder. To prepare PVDF/ $\mathrm{Ni}$ nanocomposites, PVDF powder was filled with $72 \mathrm{~nm}$ Ni particles by means of a mixing in a planetary ball mill. Content of Ni powder in composites

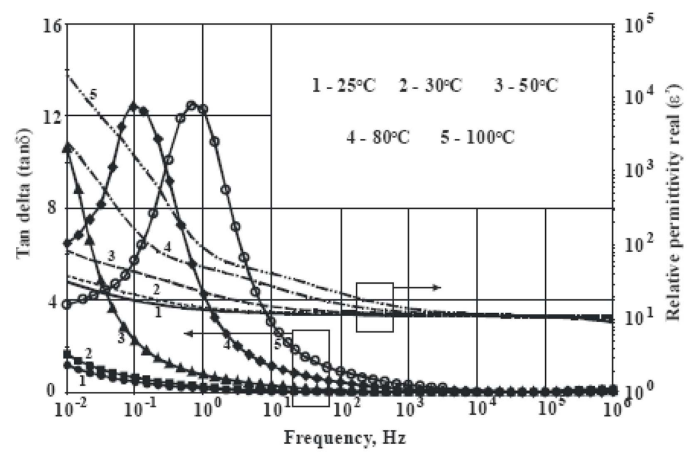

(a)

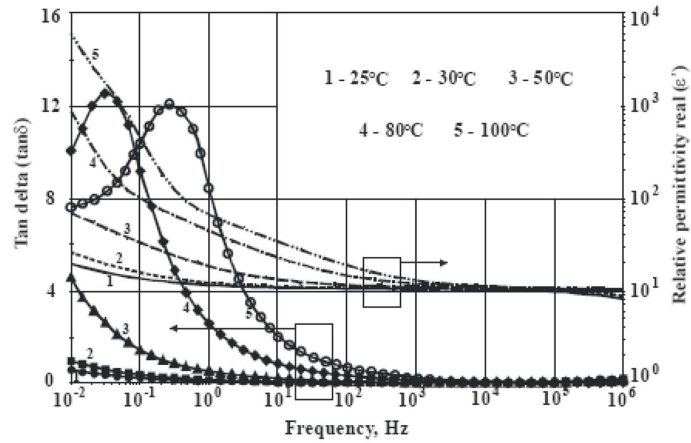

(b)

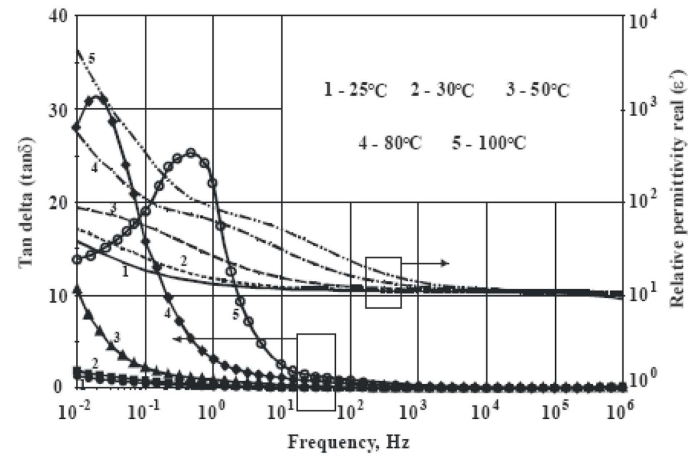

(c)

Fig. 1. Temperature - frequency dependencies of $\tan \delta$ and $\varepsilon^{\prime}$ for: a, PVDF; b, PVDF/0.2\% Ni; and c, PVDF/2.0\% Ni. 
was changed from 0.05 to $5.0 \mathrm{wt} \%$. All samples were prepared by hot pressing in a hydraulic press. Samples studied were prepared as discs $75 \mathrm{~mm}$ in diameter and thicknesses of $20 \sim 150 \mu \mathrm{m}$.

\section{Experimental Results and Discussion}

\subsection{PVDF/Ni submicrocomposites}

Temperature-frequency dependencies of $\varepsilon^{\prime}$ and $\tan \delta$ for PVDF and PVDF/Ni composites with average Ni-particles size of $200 \mathrm{~nm}$ are shown in Fig. 1.

The values of $\tan \delta_{\max }$ for composite PVDF/ $0.2 \% \mathrm{Ni}$ and PVDF do not practically differ at $\mathrm{T}=80^{\circ} \mathrm{C}$ and $100^{\circ} \mathrm{C}$. The further increase in $\mathrm{Ni}$ content to $2 \mathrm{wt} \%$ results in the increase of $\tan \delta_{\max }$ while the $\tan \delta$ peak position is practically unchangeable. Modification of PVDF matrix by $0.2 \sim 2.0 \mathrm{wt} \%$ of $\mathrm{Ni}$ does not result in visible increase of the real part $\varepsilon^{\prime}$ of the complex permittivity.

Table 1 represents the temperature dependencies of the specific volume resistivity $\rho_{\mathrm{v}}$ for PVDF/Ni composites with average Ni-particles size of $200 \mathrm{~nm}$. It can be seen that $\rho_{\mathrm{v}}$ for composite with $0.2 \mathrm{wt} \%$ of $\mathrm{Ni}$ in the temperature range from $25^{\circ} \mathrm{C}$ to $80^{\circ} \mathrm{C}$ is increased by a factor of $1.24 \sim 15$ compared to that for neat PVDF. Similar effect is observed for composite with $0.5 \mathrm{wt} \%$ of $\mathrm{Ni}$ the only difference being that the increase in $\rho_{\mathrm{v}}$ is about 1.1 2.14 compared to that for the PVDF matrix. For other composites the increase of $\rho_{\mathrm{v}}$ in comparison with PVDF becomes negligible at $\mathrm{T}>50^{\circ} \mathrm{C}$. That is, the modification of PVDF matrix by $0.2 \sim 0.5 \mathrm{wt} \% \mathrm{Ni}$ results in the
Table 2. Thermal character-istics for PVDF/Ni composites with average ni-particles size of $200 \mathrm{~nm}$

\begin{tabular}{lccc}
\hline \hline \multicolumn{1}{c}{ Composite } & $T_{m b},{ }^{\circ} \mathrm{C}$ & $T_{m},{ }^{\circ} \mathrm{C}$ & $\Delta T_{m},{ }^{\circ} \mathrm{C}$ \\
\hline PVDF & 135 & 152 & 17 \\
PVDF/0.2\% Ni & 150 & 157 & 7 \\
PVDF/0.5\% Ni & 144 & 159 & 15 \\
PVDF $/ 1.0 \% \mathrm{Ni}$ & 144 & 158 & 14 \\
PVDF/2.0\% Ni & 145 & 159 & 14 \\
\hline & $T_{d b},{ }^{\circ} \mathrm{C}$ & $T_{d},{ }^{\circ} \mathrm{C}$ & $\Delta T_{d},{ }^{\circ} \mathrm{C}$ \\
\hline PVDF & 356 & 375 & 19 \\
PVDF $/ 0.2 \% \mathrm{Ni}$ & 406 & 423 & 17 \\
PVDF/0.5\% Ni & 393 & 424 & 31 \\
PVDF $/ 1.0 \% \mathrm{Ni}$ & 388 & 425 & 37 \\
PVDF $/ 2.0 \% \mathrm{Ni}$ & 383 & 423 & 40 \\
\hline
\end{tabular}

increase of the volume resistivity of CPM' in the temperature range from $25^{\circ} \mathrm{C}$ to $80^{\circ} \mathrm{C}$ [13].

Results of DSC/TGA analysis for neat PVDF and PVDF/Ni composites are shown in Fig. 2 and Table 2 , where $T_{m}, T_{m b}$, and $\Delta T_{m}$ are the melting temperature, beginning melting temperature and melting interval, respectively; subscript $d$ in Table 2 means three similar parameters for decomposition process (heating rate of $3^{\circ} \mathrm{C} / \mathrm{min}$ ). It can be seen that there are two endothermic processes which correspond to phase transitions in a polymeric materials. The first of them (at $\sim 135-160^{\circ} \mathrm{C}$ ) is related with the melting temperature of PVDF and the latter (at $\sim 355-425^{\circ} \mathrm{C}$ ) corresponds to the decomposition temperature.

Table 2 demonstrates that the melting temperature of PVDF/Ni composites with average Ni-particles size of $200 \mathrm{~nm}$ is increased by $5 \sim 7^{\circ} \mathrm{C}$ compared with neat PVDF. That can probably mean that the degree

Table 1. Temperature dependence of $\rho_{\mathrm{v}}$ for PVDF/Ni submicrocomposites

\begin{tabular}{cccccccccc}
\hline \multirow{2}{*}{$\begin{array}{c}\mathrm{Ni} \\
\text { content, wt } \%\end{array}$} & \multicolumn{8}{c}{$\rho_{\text {o }}$ Ohm-m at $T,{ }^{\circ} \mathrm{C}$} \\
\cline { 2 - 9 } & 25 & 30 & 40 & 50 & 60 & 70 & 80 & 90 \\
\hline 0 & $2.1 \cdot 10^{12}$ & $2.2 \cdot 10^{11}$ & $3.1 \cdot 10^{10}$ & $4.4 \cdot 10^{9}$ & $1.0 \cdot 10^{9}$ & $4.6 \cdot 10^{8}$ & $2.1 \cdot 10^{8}$ & $1.5 \cdot 10^{8}$ & $5.4 \cdot 10^{7}$ \\
0.2 & $8.2 \cdot 10^{12}$ & $3.3 \cdot 10^{12}$ & $4.2 \cdot 10^{11}$ & $2.6 \cdot 10^{10}$ & $3.3 \cdot 10^{9}$ & $6.2 \cdot 10^{8}$ & $2.6 \cdot 10^{8}$ & $1.2 \cdot 10^{8}$ & $5.8 \cdot 10^{7}$ \\
0.5 & $4.5 \cdot 10^{12}$ & $4.5 \cdot 10^{11}$ & $5.1 \cdot 10^{10}$ & $6.8 \cdot 10^{9}$ & $1.0 \cdot 10^{9}$ & $5.4 \cdot 10^{8}$ & $2.3 \cdot 10^{8}$ & $9.8 \cdot 10^{7}$ & $4.9 \cdot 10^{7}$ \\
1.0 & $2.9 \cdot 10^{12}$ & $2.7 \cdot 10^{11}$ & $3.1 \cdot 10^{10}$ & $4.0 \cdot 10^{9}$ & $6.5 \cdot 10^{8}$ & $2.9 \cdot 10^{8}$ & $1.3 \cdot 10^{8}$ & $6.6 \cdot 10^{7}$ & $3.3 \cdot 10^{7}$ \\
2.0 & $2.6 \cdot 10^{12}$ & $2.9 \cdot 10^{11}$ & $3.6 \cdot 10^{10}$ & $5.2 \cdot 10^{9}$ & $8.0 \cdot 10^{8}$ & $3.3 \cdot 10^{8}$ & $1.3 \cdot 10^{8}$ & $6.5 \cdot 10^{7}$ & $2.9 \cdot 10^{7}$ \\
\hline
\end{tabular}




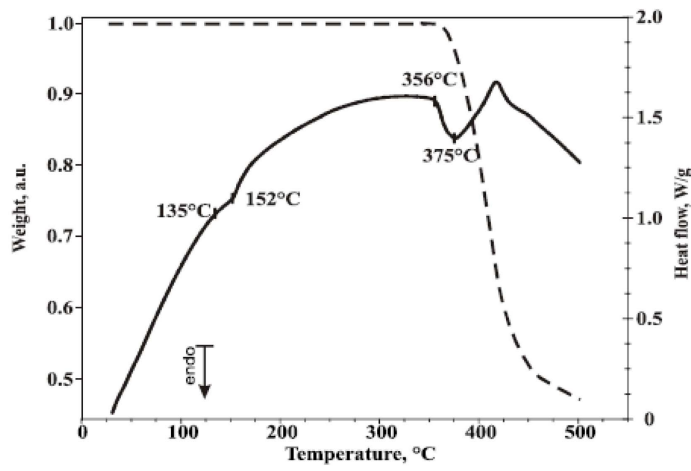

(a)

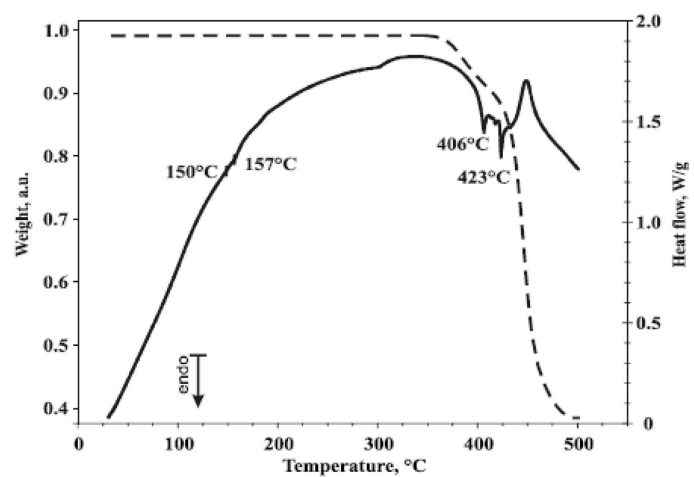

(b)

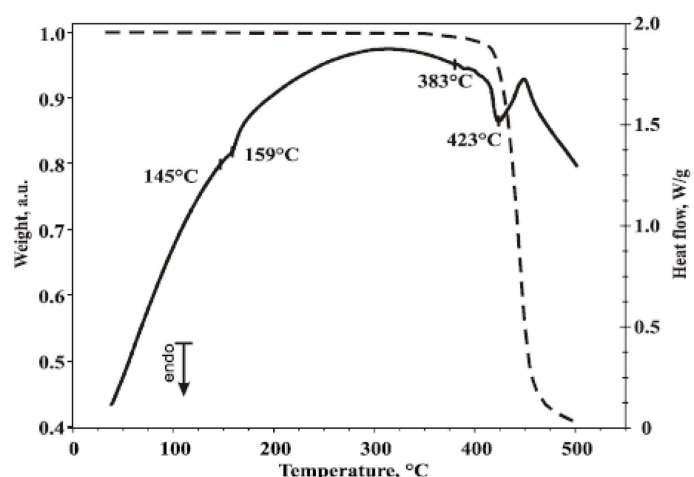

(c)

Fig. 2. DSC/TGA results for: (a) PVDF matrix, (b) 0.2 wt\% $\mathrm{Ni}$ and (c) $2.0 \mathrm{wt} \% \mathrm{Ni}$; dotted line-sample weight, and solid line-heat flow.

of crystallinity and homogeneity of sub-molecular structure for filled composites is changed compared with neat PVDF due to the formation of artificial nucleation centers [8]. The increase in $\mathrm{Ni}$ content in a polymer matrix from 0.2 to $2.0 \mathrm{wt} \%$ does not lead

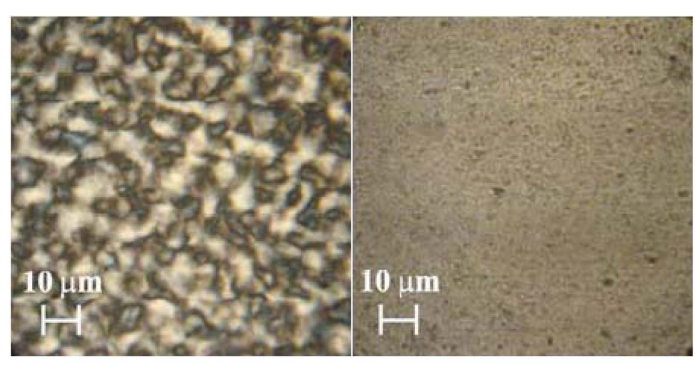

(a)

(b)

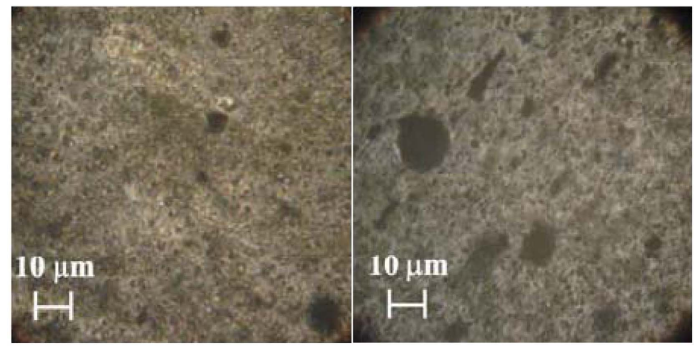

(c)

(d)

Fig. 3. Patterns of sub-molecular structures of PVDF/Ni composites at different $\mathrm{Ni}$ contents: (a) $0 \mathrm{wt} \%$, (b) 0.2 wt \%, (c) $0.5 \mathrm{wt} \%$, and (d) $2.0 \mathrm{wt} \%$.

to considerable increase in the melting temperature for composites with $\mathrm{Ni}$ content more than $0.5 \mathrm{wt} \%$ compared to composite with $0.2 \mathrm{wt} \%$ of $\mathrm{Ni}$. It can becaused by the formation of filler agglomerates. That is, modification of PVDF by Ni particles results in the increase of thermal stability of CPM'. Table 2 shows that the decomposition temperature $T_{d}$ for filled composites is increased compared with neat PVDF and it does not practically changed with increase in Ni content. Maximum value of $T_{d b}$ is observed also for composite with $0.2 \mathrm{wt} \%$ of $\mathrm{Ni}$. However the value of $T_{d b}$ is decreased with increase in Ni content. Such behavior of $T_{d}$ and $T_{d b}$ means that agglomerates of $\mathrm{Ni}$ particles in CPM' are the main reason for deterioration in the thermal properties.

Thus, the maximum thermal stability and the higher volume of $\rho_{v}$ are observed for composite with 0.2 $\mathrm{wt} \%$ of $\mathrm{Ni}$, and to some extent for $0.5 \mathrm{wt} \%$, compared to PVDF. This conclusion is well confirmed also by the experimental results of the sub-molecular 
structure study. Fig. 3 shows typical micrographs of sub-molecular structure for PVDF/Ni composites.

It can be seen that adding $\mathrm{Ni}$ into the polymeric matrix results in considerable modification of the PVDF submolecular structure. Large-size spherulite structure of PVDF matrix is transformed into a small-size spherulite one. The increase in filler content results in increase of the average size of $\mathrm{Ni}$ agglomerates. So, agglomerates for composites with $0.2 \mathrm{wt} \%$ of $\mathrm{Ni}$ either are absent in general or their average size does not exceed $3 \mu \mathrm{m}$. At $0.5 \mathrm{wt} \%$ of $\mathrm{Ni}$ the average size of $\mathrm{Ni}$ agglomerates is about 5 $\mu \mathrm{m}$ while at $2.0 \mathrm{wt} \%$ of $\mathrm{Ni}$ it is equals to $5-10 \mu \mathrm{m}$. As a result, the more homogeneous submolecular structure is formed in composite with $0.2 \mathrm{wt} \%$ of $\mathrm{Ni}$ [13]. That is, Ni particles may be considered as artificial nucleation centers modifying PVDF matrix [8].

\subsection{PVDF/Ni nanocomposites}

To compare main properties of submicro- and nanocomposites, PVDF/Ni nanocomposites with average Ni particles size of $72 \mathrm{~nm}$ were prepared. Dielectric relaxation spectra for PVDF/Ni composites with average Ni-particles size of $72 \mathrm{~nm}$ are shown in Fig. 4. It can be seen that dielectric relaxation spectra for nanocomposites do not change compared to that for previous composites the only difference being that measurement of dielectric relaxation spectra for these composites is impossible at the Ni content more than $1 \mathrm{wt} \%$ due to sharp increase in the conductivity of materials. This is caused by that particles of nanofiller possess an enormous specific surface area compared to that for submicron particles and the percolation effect is observed in samples even at low Ni content ( $\geq 1 \mathrm{wt} \%)$ in nanocomposites.

Table 3 lists the activation energy $W$ of the polarization process for PVDF/Ni nanocomposites. The activation energy was estimated from the temperature-frequency dependencies by means of the Arrhenius plot. It can be seen that the value of $W$ is close to $1.0 \mathrm{eV}$ for all nanocomposites.
Table 3. Activation energy for nanocomposites

\begin{tabular}{cc}
\hline \hline Filler content, \% & Activation energy $W \pm \sigma_{w}, \mathrm{eV}$ \\
\hline 0 & $0.983 \pm 0.016$ \\
0.05 & $0.959 \pm 0.011$ \\
0.1 & $0.986 \pm 0.005$ \\
0.5 & $0.993 \pm 0.006$ \\
1.0 & $1.023 \pm 0.008$ \\
\hline
\end{tabular}

Table 4. Thermal characteristics for PVDF/Ni (72 nm) CPM's

\begin{tabular}{lccc}
\hline \hline \multicolumn{1}{c}{ Composite } & $T_{m b},{ }^{\circ} \mathrm{C}$ & $T_{m},{ }^{\circ} \mathrm{C}$ & $\Delta T_{m},{ }^{\circ} \mathrm{C}$ \\
\hline PVDF & 123 & 159 & 36 \\
PVDF/0.05\% Ni & 128 & 159 & 31 \\
PVDF/0.1\% Ni & 128 & 159 & 31 \\
PVDF/0.2\% Ni & 128 & 159 & 31 \\
PVDF/1.0\% Ni & 131 & 160 & 29 \\
PVDF/2.0\% Ni & 128 & 159 & 31 \\
PVDF/5.0\% Ni & 127 & 159 & 32 \\
\hline & $T_{d b},{ }^{\circ} \mathrm{C}$ & $T_{d}{ }^{\circ} \mathrm{C}$ & $\Delta T_{d},{ }^{\circ} \mathrm{C}$ \\
\hline PVDF & - & 430 & - \\
PVDF/0.05\% Ni & - & 431 & - \\
PVDF/0.1\% Ni & - & 442 & - \\
PVDF/0.2\% Ni & - & 443 & - \\
PVDF/1.0\% Ni & - & 451 & - \\
PVDF/2.0\% Ni & - & 448 & - \\
PVDF/5.0\% Ni & - & 446 & - \\
\hline
\end{tabular}

DSC/TGA analysis results for neat PVDF and PVDF/Ni nanocomposites are listed in Table 4 (heating rate of $10^{\circ} \mathrm{C} / \mathrm{min}$ ).

It is obvious that the melting temperature for nanocomposites does not change with increase in the filler content from 0.05 to $5.0 \mathrm{wt} \%$ in contrast to submicro-composites. On the other hand, the decomposition temperature $T_{d}$ has been increased from $12^{\circ} \mathrm{C}$ to $21^{\circ} \mathrm{C}$ with increase in $\mathrm{Ni}$ content from 0.1 to $1.0 \mathrm{wt} \%$. In contrast to pure PVDF, $\mathrm{T}_{\mathrm{d}}$ tends to decrease with $\mathrm{Ni}$ content in PVDF/Ni composites even at low Ni levels. It confirm above mentioned assumption for submicrocomposites that deterioration of thermal properties with increase in the filler content is caused by the formation of agglomerates of Ni particles.

The results of XRD study were used for the analy- 


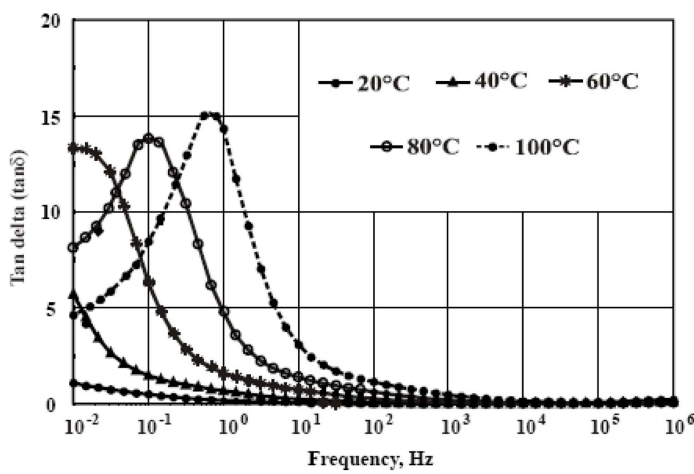

(a)

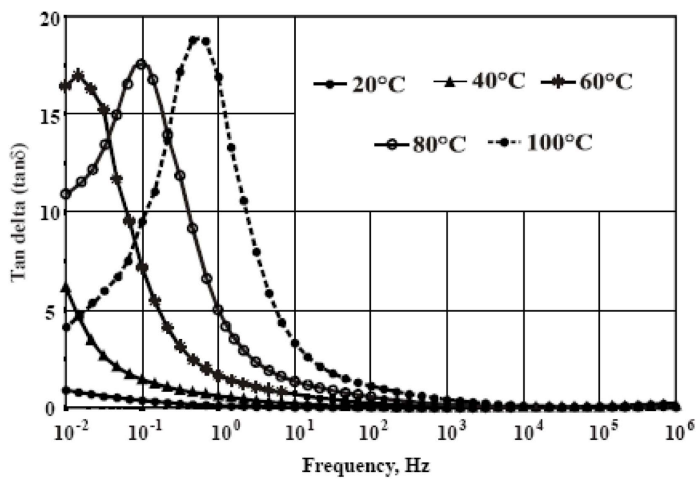

(b)

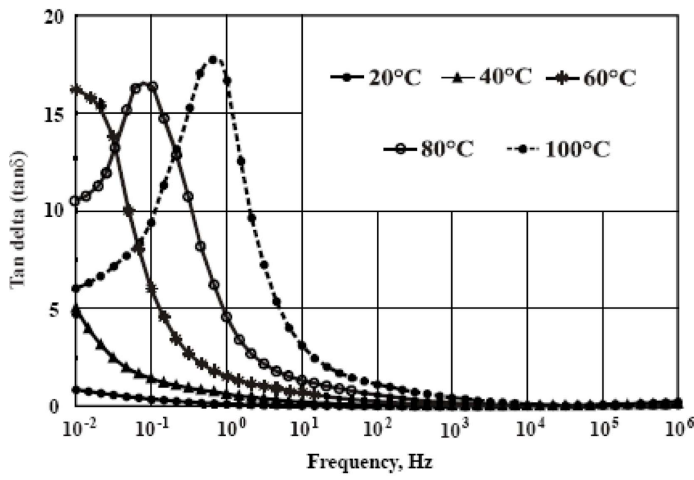

(c)

Fig. 4. Temperature-frequency dependencies of $\tan \delta$ for PVDF and nanocomposites PVDF/Ni with various filler content: (a) PVDF, (b) $0.1 \mathrm{wt} \% \mathrm{Ni}$, (b) $0.5 \mathrm{wt} \% \mathrm{Ni}$ and (c) $1.0 \mathrm{wt} \% \mathrm{Ni}$.

sis of structural properties of PVDF/Ni nanocomposites. The X-ray diffraction patterns of neat PVDF and nanocomposites are shown in Fig. 5. The weak peak centered at $18.3^{\circ}$, the sharp peak at $20.2^{\circ}$ and two weak peaks at $36.1^{\circ}$, and $40.5^{\circ}$ are characteris-

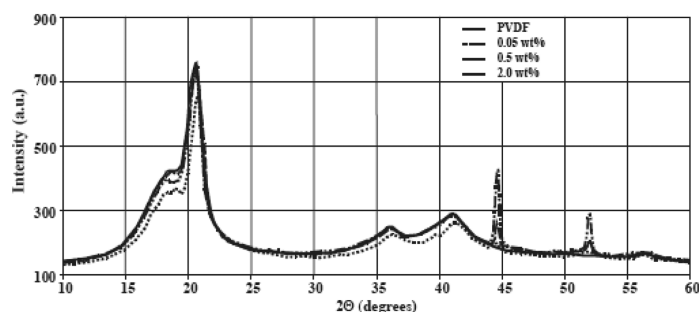

Fig. 5. XRD patterns for neat PVDF and nanocomposites with different Ni content.

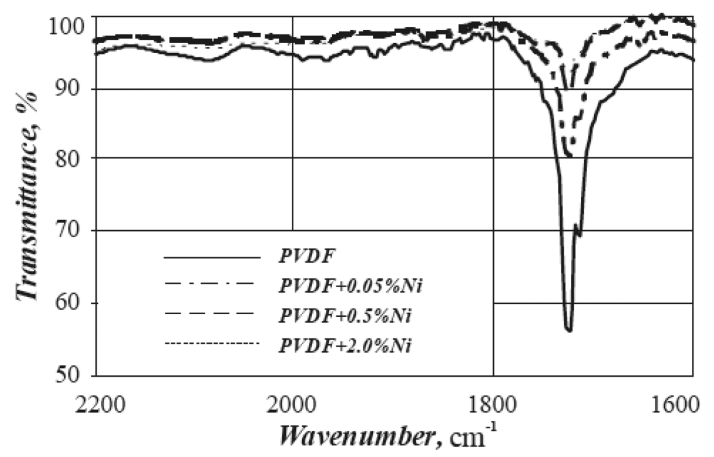

Fig. 6. FTIR-spectra for neat PVDF and nanocomposites with different $\mathrm{Ni}$ content.

tic peaks of planes (100), (020), and (021) of PVDF crystallites [14]. The characteristic peaks of nickel are clearly visible at $44.4^{\circ}$ and $51.8^{\circ}$ [15], and the intensity of these peaks is increased with $\mathrm{Ni}$ content.

One more interesting experimental fact has been found out when studying FTIR-spectra of neat PVDF and nanocomposites (Fig. 6). For all samples prepared by hot pressing method the band centered at $1723 \mathrm{~cm}^{-1}$ is observed. This characteristic band is caused by oscillations of $\mathrm{C}=\mathrm{C}$ bonds of polymeric matrix. The intensity of these oscillations is decreased with increase in Ni content in nanocomposites.

\section{Conclusions}

The main results of this study are as follows.

1. It was found that modification of PVDF by 200 $\mathrm{nm} \mathrm{Ni}$ particles results in the change of homogeneity of submolecular structure of submicro-composites. At low Ni content in PVDF the large-size spherulite 
structure of a polymeric matrix transforms into the small-size spherulite one. Ni particles are acting as an artificial nucleating agent modifying a polymeric structure.

2. Composites on the basis of PVDF matrix with a low $\mathrm{Ni}$ content (less than $0.5 \mathrm{wt} \%$ ) possess both the higher thermal stability and specific volume resistivity due to homogeneity of a sub-molecular structure.

3. Decrease in the average Ni-particles size from 200 to $72 \mathrm{~nm}$ results in the sharp increase in the conductivity of PVDF/Ni composites due to increase of the specific surface area of filler and decrease of the percolation threshold.

4. The number of defect $\mathrm{C}=\mathrm{C}$ bonds in $\mathrm{PVDF} / \mathrm{Ni}$ nanocomposites decreases with increase in the $\mathrm{Ni}$ content. The number of defect $\mathrm{C}=\mathrm{C}$ bonds in PVDF/ $\mathrm{Ni}$ nanocomposites decreases with increase in $\mathrm{Ni}$ content. This is confirmed by the decrease in oscillations intensity of the characteristic band at $1723 \mathrm{~cm}^{-1}$.

\section{Acknowledgement}

This work was supported by the Russian Special Federal Program "Scientific and Scientific-pedagogic staff of innovative Russia, 2009-2013" under contracts No. P407 and P1913.

\section{References}

[1] T. J. Lewis: IEEE Trans. Diel. Elect. Insul., 1 (1994) 812.

[2] T. Tanaka: IEEE Trans. Diel. Elect. Insul., 12 (2005) 914.

[3] S. M. Lebedev, O. S. Gefle and Y. P. Pokholkov: IEEE Trans. Diel. Elect. Insul., 12 (2005) 537.

[4] D. K. Das-Gupta and K. Doughty: Thin Solid Films, 158 (1988) 93

[5] H. L. W. Chan, Y. Chen and C. L. Choy: IEEE Trans. Diel. Elect. Insul., 3 (1996) 800.

[6] H. L. W. Chan, W. K. Chan, C. L. Choy and Y. Zhang: IEEE Trans. Diel. Elect. Insul., 5 (1998) 505.

[7] H. L. W. Chan, Q. Q. Zhang, W. Y. Ng and C. L. Choy: IEEE Trans. Diel. Elect. Insul., 7 (2000) 204.

[8] V. P. Solomko: Filled crystalline polymers, Naukova Dumka, Kiev, (1980).

[9] V. E. Gool, N. N. Turkova and M. G. Golubeva: Reports of USSR Science Academy, 199 (1971) 135.

[10] D. Bloor, K. Donnelly, P. J. Hands et al: J. Phys. D: Appl. Phys., 38 (2005) 2851.

[11] E. M. A. Jamal, P. A. Joy, P. Kurian and M. R. Anantharaman: Mater Sci and Eng. B, 156 (2009) 24.

[12] Impedance/Gain-Phase Analyzer 1260 and Dielectric Interface 1296, User guide, (2001).

[13] S. M. Lebedev, O. S. Gefle and S. N. Tkachenko: J. Electrostatics, 68 (2010) 122.

[14] P. Raghavana, X. Zhaoa, J. Manuela, G. S. Chauhana, J. H. Ahna, H. S. Ryub, H. J. Ahnb, K. W. Kimb and C. Nah: Electrochemica Acta., 55 (2010) 1347.

[15] E. M. A. Jamala, P. A. Joyb, P. Kurianc and M. R. Anantharaman: Mater Sci Eng. B, 156 (2009) 24. 